\title{
Localization of IgA and secretory component in benign tumors of the human minor salivary glands
}

\author{
Mieko Sashima, Yasunori Takeda and Atsumi Suzuki \\ Department of Oral Pathology, School of Dentistry, Izeate Medical University, \\ Uchimaru 19-1, Morioka 020, Japan
}

[Accepted for publication: October 20, 1982]

Key words: IgA / secretory component / benign tumor / minor salivary gland / PAP method

Secretory immunoglobulin A (s-IgA) is a major immunoglobulin in external body fluids of mammals and participates in an important protective function in the fluids and on mucosal surface. In the oral cavity, s-IgA is secreted from the salivary glands and may act as an inhibiter of the growth of microorganisms and as a preventer of the infection as well as peroxidase, lysozyme and lactoferrin. Recent reports ${ }^{1,2)}$ defined the transport mechanism of s-IgA in exocrine glands. According to those studies, serum IgA is synthesized locally by plasma cells in the interstitial connective tissue of the salivary glands, and dimerized with $\mathrm{J}$-chain in plasma cells before secretion. Secretory component (SC) is an additional important glycoprotein synthesized by the epithelial cells, and apparently functions as a glandular receptor for dimeric IgA. Immunohistochemical studies on localization of $\operatorname{IgA}$ and SC were made on the major salivary glands in human ${ }^{1-5)}$ and animals ${ }^{6}$, but little work has been done so far for normal tissues and tumors of the human minor salivary glands, although just one report ${ }^{7)}$ could be found in the literature. The purpose of the present study is to examine the localization of $\operatorname{IgA}$ and $\mathrm{SC}$ in normal tissues and benign tumors of the human minor salivary glands by using the peroxidase anti-peroxidase (PAP) method.

\section{Materials and Methods}

Materials: Thirty-one cases of benign tumors of the minor salivary glands were used as materials, which were dealt with our laboratory during the past twelve years. They were 30 cases of pleomorphic adenoma and 1 case of monomorphic adenoma. The age and sex distribution of these pleomorphic adenoma were reported previously ${ }^{8)}$. The original sites of pleomorphic adenoma were as follows: 22 cases in palate, 4 cases in lip and 4 cases in cheek. One case of monomorphic adenoma was palatal origin. The normal minor salivary glands, included in the biopsy or operation materials in the cases of tumor or mucocele, were also studied. All of those specimens were prepared by a conventional method, namely they were fixed in $10 \%$ formalin and were embedded in paraffin.

Immunohistochemical procedure: Paraffin section were cut at $4 \mu \mathrm{m}$ at maximum surface of the specimens. The technique used for detection of $\operatorname{IgA}$ and $\mathrm{SC}$ was PAP method with PAP kit K 505 (DAKO, s-IgA: $\alpha$ chain and secretory component specific). Furthermore, IgA (Hoechist, $\alpha$ chain specific) and SC (DAKO) for primary antiserum were also used. After PAP method each specimen was visualized by GrahamKarnovsky solution and was counterstained by methylgreen solution.

The control tests for specificity were performed by the exclusion of primary antiserum and by using normal rabbit serum or Tris' buffer solution for primary antiserum. The negative results were obtained.

\section{Results and Discussion}

Normal minor salivary glands: $\operatorname{IgA}$ and SC were localized in some parts of duct cells such as intercalated, intralobular and 
interlobular ducts of the lingual, labial and palatal minor salivary glands. Especially in some duct cells of the lingual and palatal glands, IgA and SC were distinctly positive with the granular pattern (Fig. 1). The mucous acinar cells were entirely negative for both IgA and SC. The staining intensity of $\mathrm{SC}$ was more strong than that of $\operatorname{IgA}$, while their distribution patterns were similar.
The many scattering plasma cells within the interstitial connective tissue were also positive for IgA.

In the reports ${ }^{3,4)}$ on the major salivary glands (the parotid and submandibular glands), the different localization and the intensity of $\operatorname{IgA}$ and SG were obtained in each investigator. But recently Nakamura et al. ${ }^{1)}$ reported that $\mathrm{SC}$ was present in the

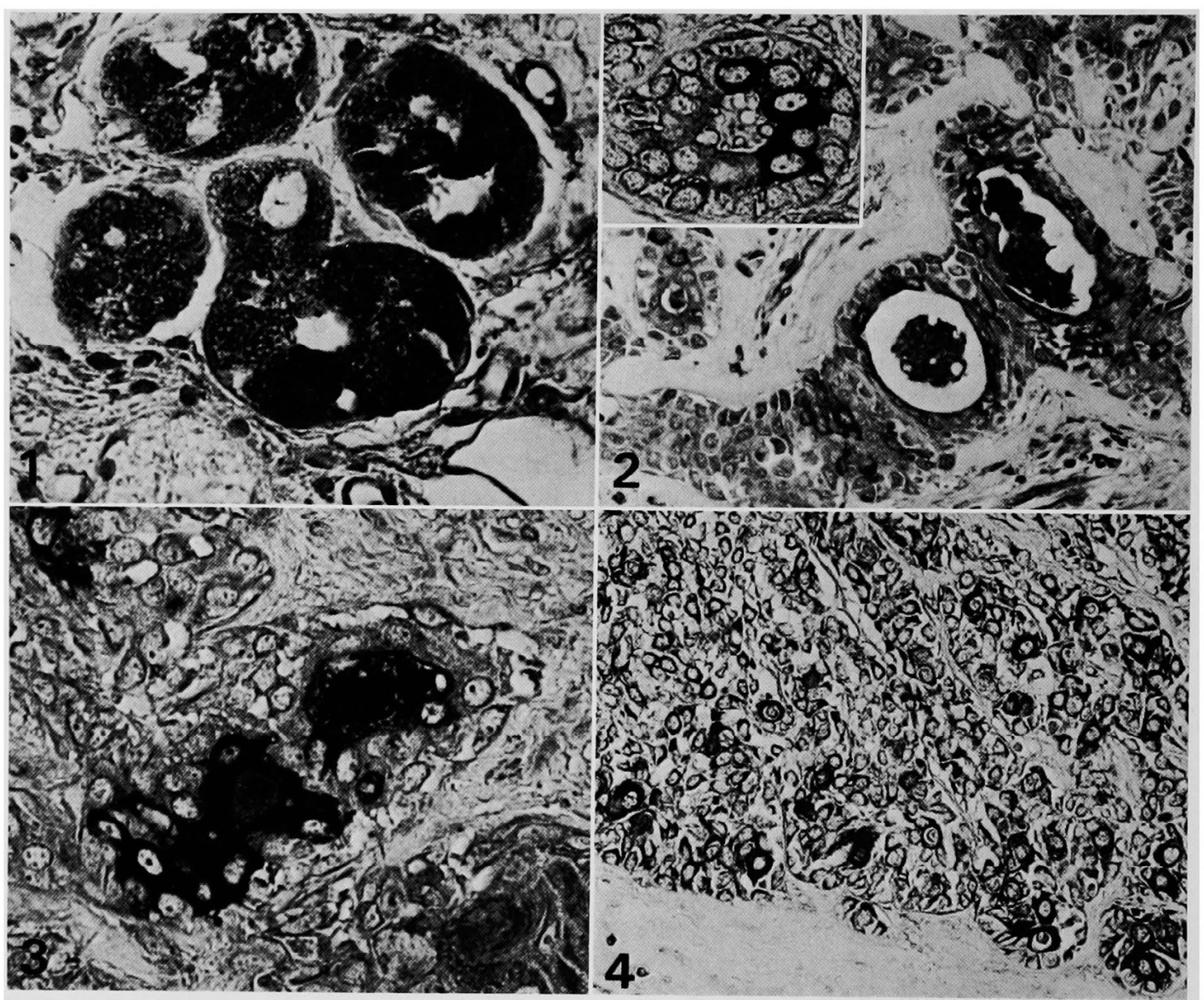

Fig. 1 Normal palatal gland. Epithelial cells of intralobular ducts are positive for SC with the granular pattern. (PAP stain for SC $\times 452$ )

Fig. 2 Pleomorphic adenoma of the buccal gland. Cuboidal tumor cells arranged in the tubular of duct-like structure and the secretory products in its lumen are positive for IgA. (PAP stain for $\operatorname{IgA} \times 226$ )

Insert: Some tumor cells located in the luminal side are positive for IgA and tumor cells located in the basal portion are negative. $(\times 452)$

Fig. 3 Pleomorphic adenoma of the palatal gland. Strongly positive for SC in part of solid cell clusters. (PAP stain for SC $\times 452$ )

Fig. 4 Monomorphic adenoma of the palatal gland. Tumor cells are moderately positive for IgA without any localization. (PAP stain for $\operatorname{IgA} \times 226$ ) 
serous acinar cells, ductal epithelial cells and secretory products in the lumen, but not in mucous acinar cells in the human major salivary glands. Korsrud and Brandtzaeg ${ }^{2)}$ also reported that SC was present in the most acinar, intercalated, and striated duct cells of the human major salivary glands except for mucous elements, and that the distribution of IgA in epithelia was similar to that of SC. On the other hand, there has so far been little report on the immunohistochemical localization of $\operatorname{IgA}$ and SC in the minor salivary glands, except Mori's report ${ }^{7)}$. Mori has studied on the human lingual gland, and reported that SC was not present in the duct cells and the mucous acini. The present study showed that IgA and SC were detected only in the epithelial cells of small ducts in part of the normal minor salivary glands. It should be necessary to make further studies on the localization of $\operatorname{IgA}$ and $\mathrm{SC}$ in various sites of the normal minor salivary glands, because these glands may play an important role in the regulation of microorganisms in the oral cavity9).

Benign tumors of the minor salivary glands: The localization of $\operatorname{IgA}$ and SC was clearly and intensely demonstrated in about one third cases of all pleomorphic adenomas. IgA and SC were positive with the granular pattern in neoplastic cells arranged in the tubular or duct-like structure, and in secretory products in its lumen. In each positive case, cuboidal cells which located in the luminal side of the tubular or duct-like structure were partially stained, whereas tumor cells located in basal portion and spindleshaped peripheral cells (myoepithelial like cells) were generally negative (Fig. 2). Positive cells for IgA and SC were also seen in some solid cell clusters (Fig. 3 ). The distribution of $\operatorname{IgA}$ was similar to that of $\mathrm{SC}$ in each case. On the other hand, the scattering tumor cells and stroma in myxoid, chondroid and hyalineous areas were negative for IgA and SC in all cases. Thus, the localization of IgA and SC were different in each histological characteristic in the pleomorphic adenoma.
The tumor cells of a monomorphic adenoma were moderately positive for $\operatorname{IgA}$ and SC without any localization (Fig. 4).

The results of the present study on the benign tumors of the minor salivary glands suggest that $\operatorname{IgA}$ and $\mathrm{SC}$ could be good indicators for the functional differentiation in the tumor cells of the minor salivary glands.

\section{References}

1) Nakamura, T. et al.: Immunocytochemical localization of secretory immunoglobulin in human parotid and submandibular glands. J. Electron Microsc. 31: 151-161, 1982.

2) Kcrsrud, F. R. and Brandtzaeg, P.: Characterization of epithelial elements in human major salivary glands by functional markers: localization of amylase, lactoferrin, lysozyme, secretory component, and secretory immunoglobulins by paired immunofluorescence staining. J. Histochem. Cytochem. 30: 657-666, 1982.

3) Rosen, R. D. et al,.: Localization of $11 \mathrm{~S}$ external secretory IgA by immunofluorescence on tissues lining the oral and respiratory passages in man. J. Immunol. 100: 706-717, 1968.

4) Kraus, F. W. and Mestecky, J.: Immunohistochemical localizaiton of amylase, lysozyme and immunoglobulins in the human parotid gland. Arch. oral Biol. 16: 781-789, 1971.

5) Kawachi, S.: Immunohistcchemical study of the human major salivary gland. Jpn. J. Oral Surg. 24: 720-732, 1978.

6) Ozawa, S. et al.: Immunopathological study on salivary gland. B-Ia. Distribution of secretory IgA and secretory component in rabbit. Nihon Univ. Dent. J. 49: 782-788, 1975.

7) Mori, M.: Imımunohistochemical study on tongue. A-I. Localization of immunoglobulins in human lingual gland. Nihon Univ. Dent. J. 52: 681--688, 1978.

8) Sashima, M., Takeda, Y. and Suzuki, A.: Histopathological study of fatty tissue in pleomorphic adenoma. J.J.S.S. 31: 259-264, 1982.

9) Crawford, J. M., Taubman, M. A. and Smith, D. J.: Minor salivary gland as a major source of secretory immunoglobulin $\mathrm{A}$ in the human oral cavity. Science 190: 1206-1209, 1975. 